\title{
A Case of Spontaneous Acute Subdural Hemorrhage Caused by a Dural Arteriovenous Fistula on the Convexity without Cortical Venous Reflux
}

\author{
Keita Yamauchi ${ }^{a}$ Shunsuke Takenaka ${ }^{b}$ Tomohiro lida ${ }^{a} \quad$ Hideki Sakai $^{a}$ \\ aDepartment of Neurosurgery, National Hospital Organization Toyohashi Medical Center, \\ Toyohashi, Japan; bepartment of Neurosurgery, Hamamatsu Rousai Hospital, Hamamatsu, Japan
}

\section{Keywords}

Spontaneous acute subdural hemorrhage $\cdot$ Dural arteriovenous fistula $\cdot$ Transarterial embolization

\begin{abstract}
Bleeding from a dural arteriovenous fistula (DAVF) typically occurs in the form of an intracerebral or subarachnoid hemorrhage. Here, we report a rare case of a DAVF with an acute subdural hematoma (ASDH). A 29-year-old male presented to the emergency department with a complaint of progressing headache and nausea, with no reported episode of head trauma. Non-contrast CT revealed a left ASDH with a moderate midline shift. Digital subtraction angiography revealed a DAVF on the left parietal convexity. The DAVF was fed by the middle meningeal artery and drained into the superior sagittal sinus and the sphenoparietal sinus via the diploic vein without cortical venous reflux. The DAVF was treated with transarterial embolization using $25 \%$ diluted $n$-butyl cyanoacrylate prior to hematoma removal. The bleeding point was confirmed on the inner surface of the dura mater. The patient recovered well without any neurological deficits.

\section{Introduction}

A dural arteriovenous fistula (DAVF) is an anomaly that develops between the meningeal arteries and dural veins, and accounts for approximately $10-15 \%$ of all intracranial vascular malformations [1]. About $20 \%$ of DAVFs present with intracranial hemorrhage [1,2], which is usually in the form of an intracerebral or subarachnoid hemorrhage $[3,4]$. The intracranial hemorrhage due to DAVF often 


\section{Case Reports in Neurology}

Yamauchi et al.: Subdural Hematoma by a Dural Arteriovenous Fistula

associates with cortical venous reflux [5, 6]. Here, we report a rare case of spontaneous acute subdural hemorrhage (ASDH) caused by a DAVF on the convexity without cortical venous reflux.

\section{Case Report/Case Presentation}

A 29-year-old male presented to our emergency department with a complaint of severe headache and nausea that had been progressing for 2 days; he reported no history of head trauma. The patient's medical history was unremarkable. On arrival, his Glasgow Coma Scale was 14 points and he exhibited no focal neurological symptoms. His pupils were isochoric and photoreactive.

A head plain computed tomography (CT) revealed an ASDH in the left parietal region with a moderate midline shift (Fig. 1a, b). Laboratory analysis revealed a mild elevation of D-dimer $(25.1 \mu \mathrm{g} / \mathrm{mL})$ and fibrin/fibrinogen degradation products (FDP; $4.30 \mu \mathrm{g} / \mathrm{mL}$ ). A CT angiogram showed no remarkable abnormality in his intracranial vasculature. Based on these findings, we performed digital subtraction angiography, and a left external carotid angiogram revealed a DAVF located in the left parietal convexity (Fig. 1c).

We performed an endovascular transarterial embolization prior to the craniotomy. A 6-Fr sheath introducer was placed at right femoral artery. After systemic heparinization, a 6-Fr guiding catheter was introduced into the left external carotid artery. A flow-directed microcatheter (Marathon, Medtronic Japan Co., Ltd.) was introduced into posterior branch of the middle meningeal artery. The main feeding artery was the posterior branch of the middle meningeal artery, and the main draining vessels were the superior sagittal and sphenoparietal sinuses via the diploic veins. There was no sign of the cortical venous reflux (Fig. $2 a$, b). The DAVF was successfully embolized using $25 \%$ diluted n-butyl cyanoacrylate (NBCA) (Fig. 2c, d). The bone window and 3D reconstructed brain CT showed the distribution of NBCA in accordance with hematoma location (Fig. 3a, b). Temporoparietal craniotomy was subsequently performed (Fig. 3c). The adhesion between the bone flap and dura mater was not so tight. We confirmed the shunt point embolized with NBCA on the outer surface of the dura mater (Fig. 3a, b). The ASDH was easily removed with no bleeding point or laceration of arachnoid membrane on the surface of the brain cortex. However, there was a clot adhesion on the inner surface of shunt point indicating the bleeding point (Fig. 3e).

The patient recovered well without any neurological deficits, and he was discharged home approximately 4 weeks after undergoing craniotomy.

\section{Discussion/Conclusion}

We describe a rare case of DAVF with ASDH without cortical venous reflux. Jolink et al. [3] reviewed the literature about DAVFs with intracranial hemorrhage from January 1980 to April 2015 and reported that subdural hemorrhage accounts for $6 \%$ of them.

There are several case studies in the literature that report DAVFs with ASDH [1, 4, 7-11]. Saito et al. [10] reviewed 9 cases of DAVF with ASDH. Seven of the 9 cases were classified as type III or IV according to the Cognard classification [6], indicating that the DAVFs had direct venous drainage into the cortical veins. In fact, 4 of the 9 cases were associated with a subcortical hematoma. They speculated that the ASDHs resulted from the laceration of the arachnoid and pia mater following a rupture of the subpial vein or dilated veins in the subdural space induced by venous hypertension [10].

In the present case, the DAVF demonstrated no signs of cortical venous reflux. In addition, intraoperative findings revealed that the bleeding point was the dural vein at the inner surface of the dura mater. We speculate that the dural vein dilation was induced by the occlusion of other drainage routes. Thus, the diploic veins might work as alternative drainage route when other routes are 
occluded. The elevation of FDP and D-dimer levels may be an indicator of the thrombotic occlusion of the drainage route.

We describe a rare case of DAVF with ASDH without cortical venous reflux. Based on the outcome of this case, if time permits, digital subtraction angiography should be considered in cases of nontraumatic ASDH.

\section{Statement of Ethics}

The authors have no ethical conflicts to disclose. The patient was informed and has given us his consent for the publication of the case.

\section{Disclosure Statement}

The authors have no conflicts of interest to declare.

\section{Funding Sources}

The authors have no funding sources to disclose.

\section{Author Contributions}

All authors made substantial contributions to the study. K.Y. examined the patient, participated in the treatment of the patient, and drafted the manuscript. K.Y. and T.I. and H.S. performed the endovascular treatment. K.Y., S.T. and T.I. performed the surgical treatment. S.T., T.I. and H.S. revised the manuscript for important intellectual content.

\section{References}

1 Maiuri F, Iaconetta G, Sardo L, Briganti F. Dural arteriovenous malformation associated with recurrent subdural haematoma and intracranial hypertension. Br J Neurosurg. 2001 Jun;15(3):273-6.

2 Davies MA, TerBrugge K, Willinsky R, Coyne T, Saleh J, Wallace MC. The validity of classification for the clinical presentation of intracranial dural arteriovenous fistulas. J Neurosurg. 1996 Nov;85(5):830-7.

3 Jolink WM, van Dijk JM, van Asch CJ, de Kort GA, Algra A, Groen RJ, et al. Outcome after intracranial haemorrhage from dural arteriovenous fistulae; a systematic review and case-series. J Neurol. 2015 Dec;262(12):2678-83.

4 Ogawa K, Oishi M, Mizutani T, Maejima S, Mori T. Dural arteriovenous fistula on the convexity presenting with pure acute subdural hematoma. Acta Neurol Belg. 2010 Jun;110(2):190-2.

5 Borden JA, Wu JK, Shucart WA. A proposed classification for spinal and cranial dural arteriovenous fistulous malformations and implications for treatment. J Neurosurg. 1995 Feb;82(2):166-79.

6 Cognard C, Gobin YP, Pierot L, Bailly AL, Houdart E, Casasco A, et al. Cerebral dural arteriovenous fistulas: clinical and angiographic correlation with a revised classification of venous drainage. Radiology. 1995 Mar;194(3):671-80.

7 Duffau H, Lopes M, Janosevic V, Sichez JP, Faillot T, Capelle L, et al. Early rebleeding from intracranial dural arteriovenous fistulas: report of 20 cases and review of the literature. J Neurosurg. 1999 Jan;90(1):78-84.

8 Kitazono M, Yamane K, Toyota A, Okita S, Kumano K, Hashimoto N. [A case of dural arteriovenous fistula associated with subcortical and subdural hemorrhage]. No Shinkei Geka. 2010 Aug;38(8):757-62.

9 Kohyama S, Ishihara S, Yamane F, Kanazawa R, Ishihara H. Dural arteriovenous fistula presenting as an acute subdural hemorrhage that subsequently progressed to a chronic subdural hemorrhage: case report. Minim Invasive Neurosurg. 2009 Feb;52(1):36-8.

10 Saito A, Kawaguchi T, Sasaki T, Nishijima M. A case of dural arteriovenous fistula presenting as acute subdural hematoma. Case Rep Neurol. 2014 Apr;6(1):122-5. 


\section{Case Reports in Neurology}

11 de Aguiar GB, Veiga JC, Silva JM, Conti ML. Spontaneous acute subdural hematoma: A rare presentation of a dural intracranial fistula. J Clin Neurosci. 2016 Mar;25:159-60.
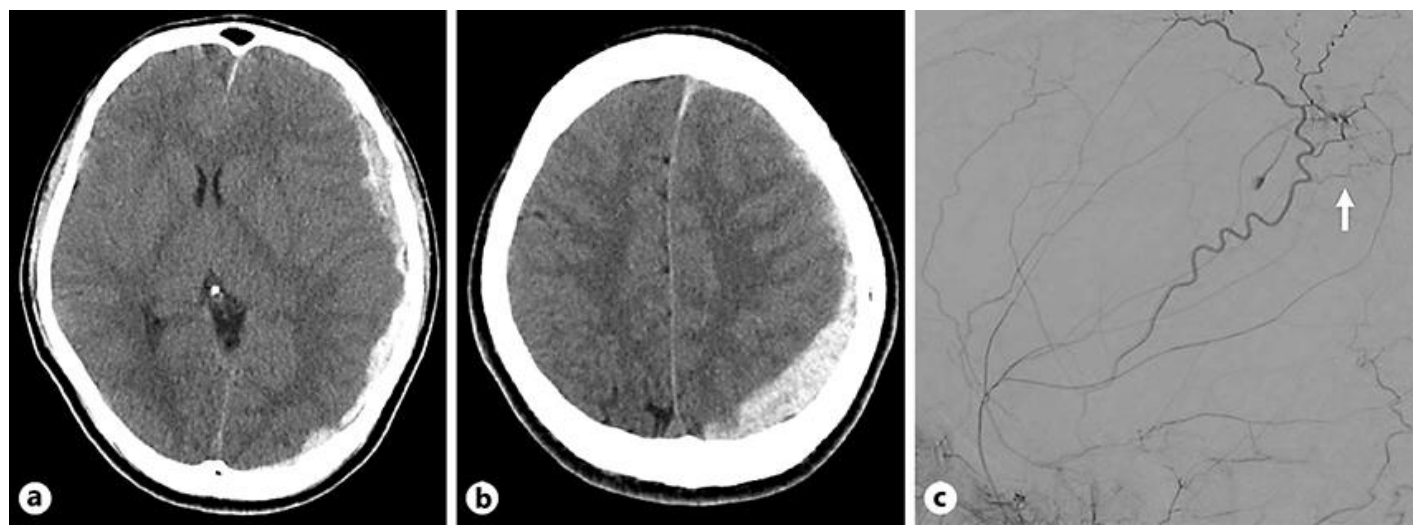

Fig. 1. a, b Non-contrast brain CT on admission demonstrating a left acute subdural hematoma on the parietal region with moderate midline shift. c Lateral view of the left external cervical angiogram revealed the dural arteriovenous fistula on the parietal convexity (white arrow). 

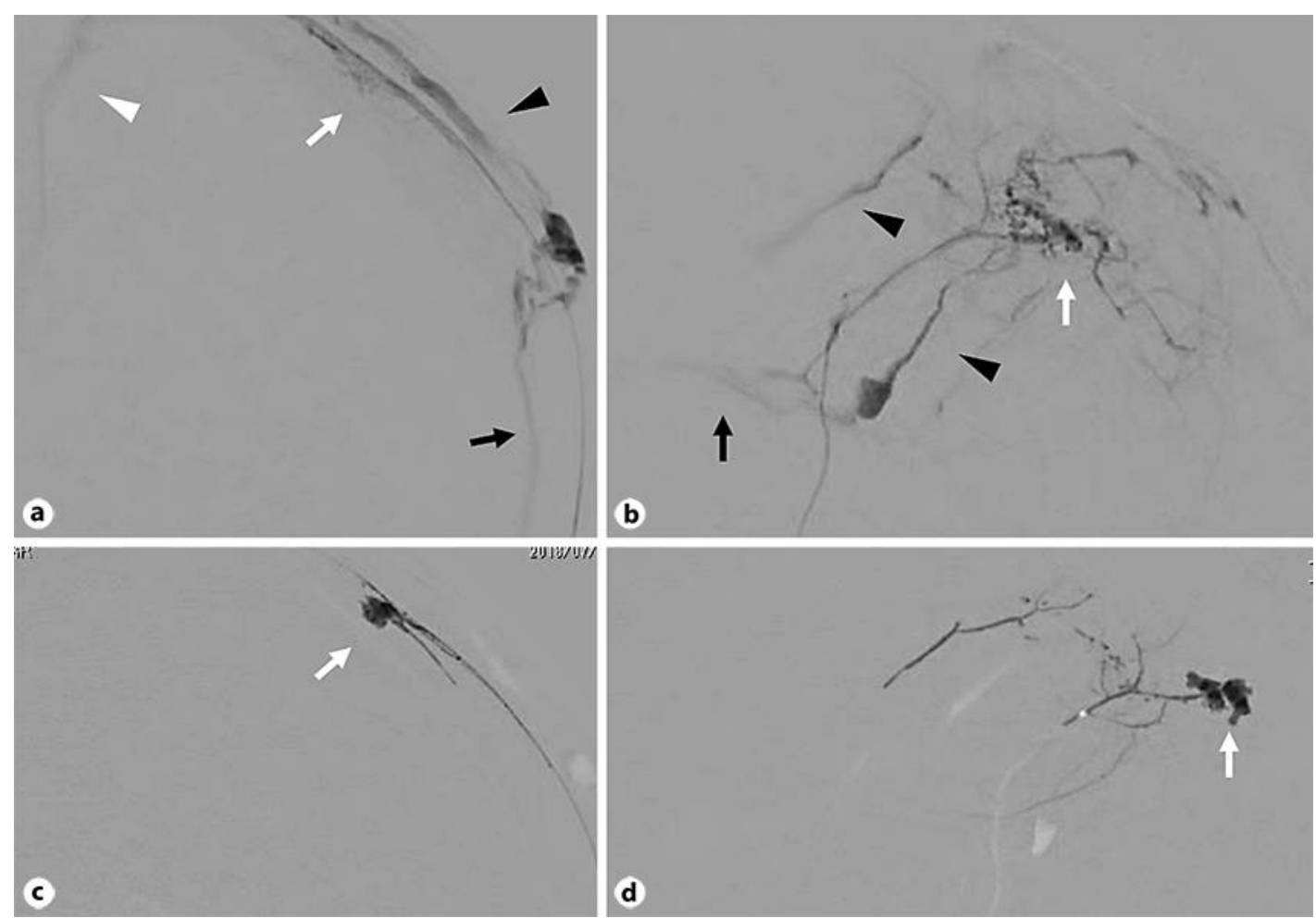

Fig. 2. Anteroposterior (a) and lateral view (b) of super selective angiogram via microcatheter placed at the posterior branch of the middle meningeal artery. White arrows show the shunt point. Shunt flow was drained into superior sagittal sinus (white arrow head) and sphenoparietal sinus (black arrows) via diploic veins (black arrow heads). Anteroposterior (c) and lateral view (d) of the angiogram during transarterial embolization using $25 \%$ diluted n-butyl cyanoacrylate. The shunt point (white arrows) was completely embolized. 


\section{Case Reports in Neurology

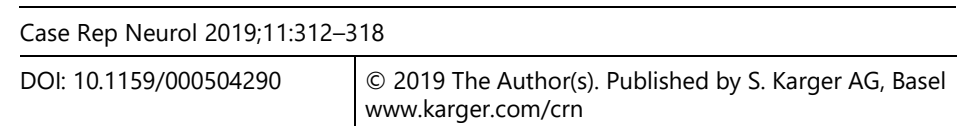

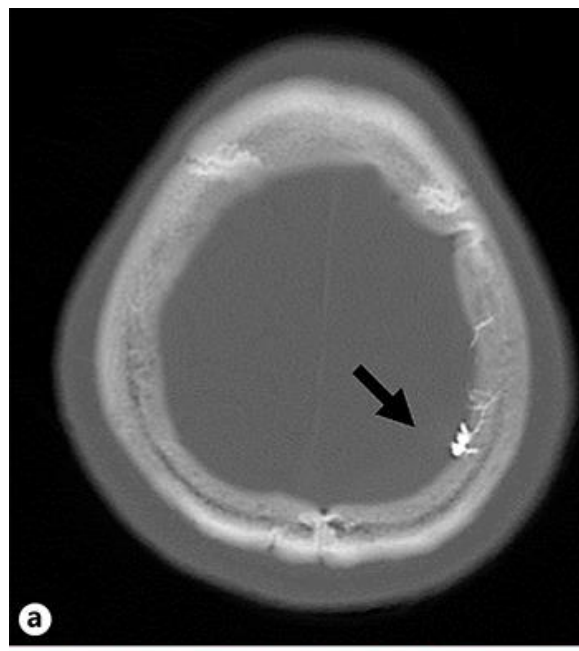
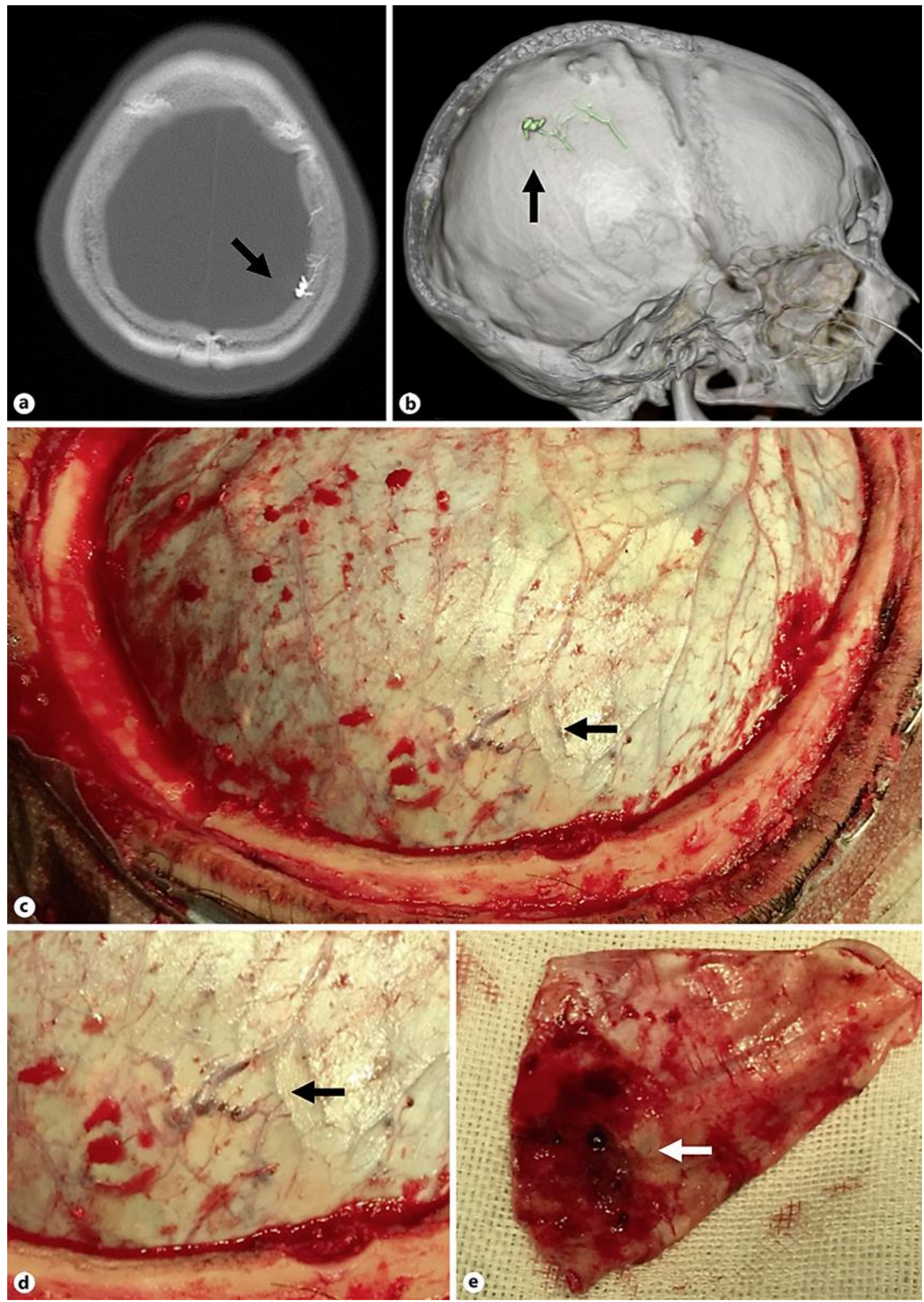
Yamauchi et al.: Subdural Hematoma by a Dural Arteriovenous Fistula

Fig. 3. Bone window (a) and 3D reconstructed non-contrast brain CT (b) after transarterial embolization showing the distribution of n-butyl cyanoaclylate in accordance with hematoma location (black arrows). Gross (c) and closed (d) findings of the outer surface of the dura matter. Black arrows indicate the shunt point embolized using n-butyl cyanoacrylate. The inner side of the shunt point (e) was covered with clot (white arrow). 